\title{
EFFECTS OF AMPHETAMINE, COCAINE, AND EPHEDRINE ON THE SEDATIVE AND HYPOTENSIVE ACTION OF RESERPINE IN RABBIT
}

\author{
KIRO SHIMAMOTO AND HIROMICHI TORII
}

Department of Pharmacology, Faculty of Medicine, Kyoto University, Kyoto

Received for publication February 17, 1961

The sedative and hypotensive effects of reserpine on experimental animals have been affirmed by many authors (1-3). Though the mechanism of action of reserpine to induce those effects was not fully elucidated, some experimental evidence revealed that the hypotensive effect of reserpine was derived from a central mechanism. It has already been shown that the pressor responses of the cat and dog to bilateral carotid occulsion or to stimulation of central end of the cut cervical vagus nerve are depressed by the intravenous injection of reserpine $(1,2)$. Bhargava and Borison (4) also showed that the pressor response to stimulation of the medulla oblongata was depressed by reserpine. Harrison and Goth (5) were the first to conclude that reserpine depressed the pressor response to stimulation of the hypothalamus. On the other hand, Anand $a t$ al. (6) and Schneider (7) could not show the depressing effect of reserpine on the hypothalamus, and it was supposed that the inconsistent results concerning the effects of reserpine on the pressor response to stimulation of the central nervous system were ascribable partially to the slow onset of the reserpine action. In their experiments, the effects of reserpine were obtained only 5 to 6 hours after the injection.

It has also been shown by many authors (8-12) that the administration of reserpine releases catecholamines or serotonin from tissues, and consequently induces depletion of the amines. From the results that the injected reserpine disappeared from the circulating blood and tissues before the full development of its sedative and hypotensive effect $(13,14)$, the selective pharmacological action of reserpine was considered to be in some relation with the depletion of the naturally occurring amines from tissues.

In the present experiments, the effects of reserpine on the pressor response to stimulation of the thalamic and hypothalamic nuclei were studied. Some of the results obtained have already been reported by Torii $(15,16)$, one of the authors.

Brodie et al. (17) and Chessin et al. (18) showed that the previous injection of iproniazid, a potent in vitro monoamine oxidase inhibitor, modified the characteristic sedation by reserpine to a marked motor excitation in rats and rabbits. The present authors have already confirmed that the intraperitoneal injection of 0.1 to $1.0 \mathrm{mg} / \mathrm{kg}$ of reserpine often induced a motor excitement and occasionally even a convulsion in mice. In the present report, the effects of reserpine on the behavior of the rabbit pretreated with iproniazid were also studied. Furthermore, the effects of the indirect sympathomimetic drugs - 
such as cocaine, amphetamine and ephedrine, which are generally considered to have some inhibitory effect on monoamine oxidase activity - on the sedative and hypotensive action of reserpine were also tested.

\section{METHODS}

Rabbits weighing 2 to $4 \mathrm{~kg}$ were used throughout the experiments.

\section{1) Behavioral effects of reserpine}

The normal unanesthetized rabbit was subjected to unrestrained spontaneous movement and behavior. After observing the normal behavior of the animal for 30 minutes or longer, reserpine in doses of 0.1 to $3.0 \mathrm{mg} / \mathrm{kg}$ was injected intravenously or intracarotidally. For the intravenous injection of the drug the ear marginal vein was used. For the purpose of facilitating repeated intracarotid injections, both common carotid arteries were exposed and fixed outside or just underneath the skin of the neck 2 to 3 days before the first injection. The behavior of the animal was observed over 2 to 3 days from the moment of injection to a full recovery in general conditions.

\section{2) Blood pressure in the urethanized rabbit}

Rabbits, anesthetized with the intraperitoneal injection of $1.0 \mathrm{~g} / \mathrm{kg}$ of urethane, were used. The head of the animal was fixed in the stereotaxic instrument of Sawyer et al. (19). Arterial blood pressure from one common carotid artery was recorded on the kymograph via mercury manometer. The effects of intravenous and intracarotid administration of reserpine on the blocd pressure level, on the pressor responses to stimulation of the contralateral thalamic (Nucleus dorsomedialis, and ventromedialis) and hypothalamic (Pars anteromedialis, and posteromedialis) nuclei, which were considered as of adrenergic origin by Shimamoto and Oyaizu (20), and on the pressor response to stimulation of the peripheral end of the sectioned splanchnic nerve were observed. For the purpose of stimulation of the thalamic and hypothalamic nuclei, submaximal square wave impulses were used at the frequency of 50 to 100 per second, and duration of 0.1 to $0.2 \mathrm{msec}$. When the splanchnic nerve was stimulated, the stimulus parameters were 20 per second in frequency, $1 \mathrm{msec}$ in duration and submaximal in intensity.

\section{3) Drugs employed}

Reserpine was used in doses of 0.1 to $3.0 \mathrm{mg} / \mathrm{kg}$ for the intravenous injection and 0.05 to $0.1 \mathrm{mg} / \mathrm{kg}$ for the intracarotid injection. Iproniazid, czcaine, amphetamine or ephedrine was injected intravenouly, intracarotidally and intraperitoneally prior to reserpine. The time intervals between injections ard the doses empolyed are given under Results.

\section{RESULTS}

\section{Effects of Reserpine on the Behavior of the Unanesthetized Rabbit}

\section{1) Effects of the intravenous injection}

The intravenous injection of reserpine in a dose of $1.0 \mathrm{mg} / \mathrm{kg}$ to the unanesthetized rabbit caused a sedation, namely, a decrease in spontaneous movements with a concomitant 
manifestation of ptosis and miosis. These sedative effects developed gradually one to two hours after the injection and became more and more conspicuous with the lapse of time. However, the sedate animal, which had received reserpine 10 to 20 hours previously, responded well to nociceptive mechanical stimuli with a retarded avoidance. The righting, corneal and pinna reflex remained unimpaired. During this sedative phase, the animal was attacked by severe diarrhea and a marked fall of the body temperature. One to two days thereafter, the animal resumed normal spontaneous movements and behavior. Development and restoration of the ptosis usually appeared in parallel to those of the depression in spontaneous movements.

\section{2) Effects of the intracarot id injection}

Reserpine in a dose of $0.1 \mathrm{mg} / \mathrm{kg}$, one-tenth of the intravenous dose, was injected into the common carotid artery unilaterally or bilaterally. Irrespective of the injection side, a marked miosis developed in both eyes soon after the injection and lasted over one or two hours. However, the sedation which usually occurred after the intravenous injection of reserpine was never obtained. Judging from the motor movements and avoidance reflex to nociceptive stimuli, the animal was rather excited. Even 10 to 20 hours after the injection, the animal showed normal to rather slightly increased movements and no sign of sedation.

\section{3) Effects of iproniazid on the sedative action of reserpine}

The intraperitoneal injection of iproniazid in doses of 50 to $100 \mathrm{mg} / \mathrm{kg}$ in unanesthetized rabbits did not affect spontaneous movements nor sympathetic activities on the day of or the day after the injection. When reserpine was administered in a dose of $1 \mathrm{mg} / \mathrm{kg}$ subcutaneously or intravenouly to the animal which had received iproniazid 24 hours previously, a marked increase in locomotor movements and an obvious excitation of the sympathetic activity such as piloerection, mydriasis and exophthalmos were observed. These excitatory effects of reserpine in the iproniazid-treated animal appeared quickly and lasted over about one hour. After the excitatory effects of reserpine were over, the animal fell into a sedative state, as with after the intravenous injection of reserpine to the animal without iproniazid. This sedation seemed to develop more rapidly than that in the latter. Ten to 20 hours after the injection of reserpine, the animal showed a typical sedation which, however, differed from that of reserpine alone in that the animal responded to mechanical stimuli with locomotor movements for a while and with a disappearance of the ptosis. Such locomotor responses were reproducible on nociceptive mechanical stimuli throughout the period of sedation. One to 2 days thereafter, the sedative effects were lost completely.

The intracarotid injection of reserpine in the dose of $0.1 \mathrm{mg} / \mathrm{kg}$ again did not produce sedation in the animal pretreated with 5 to $10 \mathrm{mg} / \mathrm{kg}$ iproniazid intracarotidally. The animal was probably rather excited. Even 10 to 20 hours after the injection of reserpine the animal did not show signs of sedation. 
4) Effects of cacaine, amphetamine and ephedrine on the sedative action of reserpine

Not only iproniazid, but also cccaine, amphetamine or ephedrine injected intravenously or intracarotidally modified the response to reserpine. The principal effects of the intravenous injection of reserpine on the unanesthetized animal, which had received amphetamine $(0.5$ to $1.0 \mathrm{mg} / \mathrm{kg})$, cocaine $(2.0 \mathrm{mg} / \mathrm{kg})$ or ephedrine $(0.5 \mathrm{mg} / \mathrm{kg})$ intravenously 30 minutes to 1 hour previously and had already shown some signs of increased movement and sympathetic excitations such as mydriasis and piloerection, were a marked increase in locomotor movements occasionally accompanied by jumping movements, and pronounced sympathetic manifestations. These excitatory effects resulting from the previously administered sympathomimetic substances reached their maxima within 10 to 20 minutes and persisted for 1.5 to 2 hours. Ten to 20 hours after the reserpine injection the animal showed the characteristic sedation as seen in the iproniazid-treated animal. When applying mechanical stimuli, the animal responded with normal movements and a dilatation of the eyclid for a while and then returned to a sedative state.

On the other hand, the intravenous injection of $1.0 \mathrm{mg} / \mathrm{kg}$ of amphetamine, $2.0 \mathrm{mg} / \mathrm{kg}$ of cocaine or $0.5 \mathrm{mg} / \mathrm{kg}$ of ephedrine aroused or awaked the reserpine sedate animal. This arousal lasted almost as long as the excitatory effect of the sympathomimetics in the normal animal. There was no marked difference among the effects of these sympathomimetics, except that ephedrine induced a stronger sympathetic excitation and a less increase in the spontaneous movement; cocaine showed intermediate effects.

The intracarotid injection of amphetamine $(0.05$ to $0.1 \mathrm{mg} / \mathrm{kg})$, cocaine $(0.2 \mathrm{mg} / \mathrm{kg})$ to unanesthetized normal rabbits caused a similar sympathetic and motor excitement to that seen after the intravenous injection. Among the three, ephedrine produced the strongest sympathetic excitation, and amphetamine the most pronounced motor excitation. The intracarotid injection of $0.1 \mathrm{mg} / \mathrm{kg}$ of reserpine to the animal treated with amphetamine, cocaine or ephedrine 1 to 2 hours previously produced miosis, piloerection and a slight increase in spontaneous movements. However, the miosis was short-lasting. As time passed, the motor excitement was also reduced in degree, and 2 to 3 hours after the injection of reserpine the animal fell into a fully sedative state which lasted for 10 to 20 hours. Even in this sedative condition, the animal responded promptly to mechanical stimuli and soon afterwards returned to the sedative state. These effects were similar to those observed in the animal which received reserpine after pretreatment with amphetamine, cocaine or ephedrine intravenously.

It was supposed that though the animal having received amphetamine, cocaine or ephedrine became sedate following the intravenous or intracarotid injection of reserpine, the sedative effect might not have been a true but masked one, because nociceptive mechanical stimuli applied in the stage of the apparent sedation could evoke a pattern of motor movements only for a while. 


\section{Effects of Reserpine on the Pressor Response to Stimulation of the Thalamic and Hypathalamic Nuclei and of the Splanchnic Norve}

\section{1) Effects of reserpine on the carotid blood pressure}

The intravenous $(1.0$ to $3.0 \mathrm{mg} / \mathrm{kg})$ or intracarotid $(0.1 \mathrm{mg} / \mathrm{kg})$ injection of resserpine at first induced neither hyper- nor hypotension in any appreciable range. However, as time passed the blood pressure gradually dropped. The pretreatment with iproniazid in doses of 50 to $100 \mathrm{mg} / \mathrm{kg}$ did not affect the blood pressure effect of reserpine. On the other hand, the pretreatment with amphetamine, cocaine or ephedrine modified the depressor action of intravenously administered reserpine to a pressor one. The blood pressure rise was the range of 10 to $20 \mathrm{mmHg}$. The result is shown in Fig. 1 . The pretreatment with these agents did not mcdify the effect of intracarotid injection of reserpine. It is worthy of mention that the blocd pressure level of the animal which had recsived reserpine intravenously 10 to 20 hours previously was comparatively low, and in the intracarotidally administered animal comparatively high.

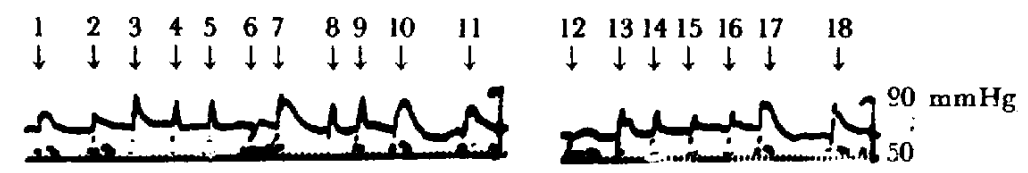

FIG. 1. The effect of the intravenous injection of $1.0 \mathrm{mg} / \mathrm{kg}$ of reserpine on the carotid pressure of the urethanized rabbit receiving $0.5 \mathrm{mg} / \mathrm{kg}$ of amphetamine 1 hour previously.

DM : Nucleus dorsomedialis thalami

VM : Nucleus ventromedialis thalami

STH : Pars posteromedialis hypothalami

Ad : Adrenaline

NAd : Noradrenaline

Time Scale : 1 min
1. Ad $3 \gamma / \mathbf{k g}$
6. Amphetamine $0.5 \mathrm{mg} / \mathrm{kg}$
11. NAd $6 r / \mathbf{k g}$
16. STH
2. NAd $6 r / \mathrm{kg}$
7. DM
12. Reserpine $1.0 \mathrm{mg} / \mathrm{kg}$
17. Ad $3 \gamma / \mathrm{kg}$
3. $\mathrm{DM}$
8. VM
13. DM
18. NAd $6 r / \mathrm{kg}$
4. $V M$
9. STH
5. STH
10. Ad $3 r / \mathrm{kg}$
14. VM
15. STH

2) Effects of reserpine on the pressor response to stimulation of the thalamic and hypothalamic nuclei and of the splanchnic nerve

The intravenous injection of $1.0 \mathrm{mg} / \mathrm{kg}$ of reserpine did not always affect the pressor responses to stimulation of the thalamic and hypothalamic nuclei and of the splanchnic nerve, but rather slightly potentiated them during the first half hour after the injection. Afterwards the pressor responses were gradually depressed but never abolished within 3 to 4 hours after the injection (Fig. 2). Ten to 20 hours later the animal did not respond even to maximal stimulation, and if any, only a slight rise was seen. The mydriasis which usually coincided with the blood pressure rise was never observed. Figure 3 shows the depression of the pressor responses to stimulation of the hypothalamus, thalamus and splanchnic nerve 10 hours after the intravenous injection of $1.0 \mathrm{mg} / \mathrm{kg}$ of reserpine. 
A

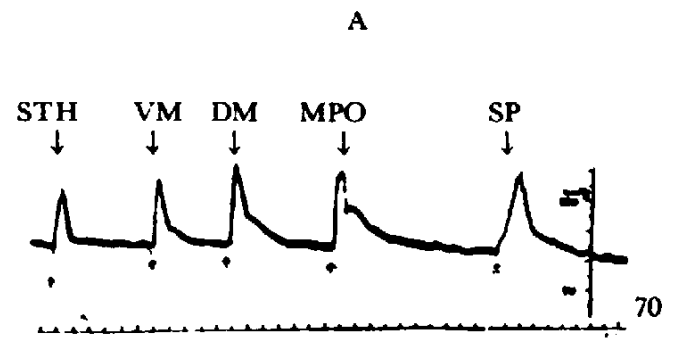

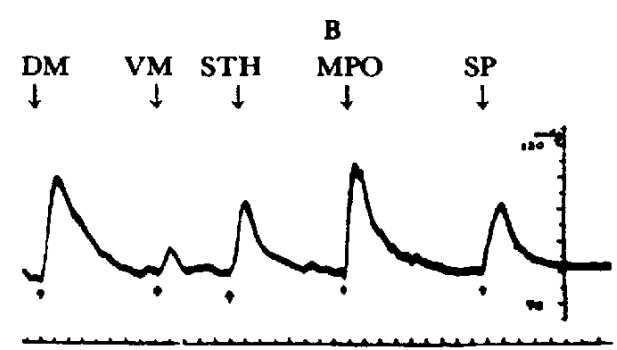

FiG. 2. The effects of the intravenous injection of $1.0 \mathrm{mg} / \mathrm{kg}$ of reserpine on the pressor responses of the urethanized rabbit to stimulation of the thalamus, hypothalamus and splanchnic nerve ( 3 hours after reserpine injection).

A : Control

B : 3 hours after reserpine injection

MPO : Pars anteromedialis hypothalami

SP : Splanchnic nerve

Time Scale : 1 min

In contrast with the marked depression after the intravenous injection, the rise of blood pressure in response to stimulation of the structures described above was not significantly affected by the intracarotid injection of reserpine even 10 to 20 hours later.

Previous treatment with 50 to $100 \mathrm{mg} / \mathrm{kg}$ of iproniazid did not significantly alter the effects of the intravenous or intracarotid injection of reserpine.

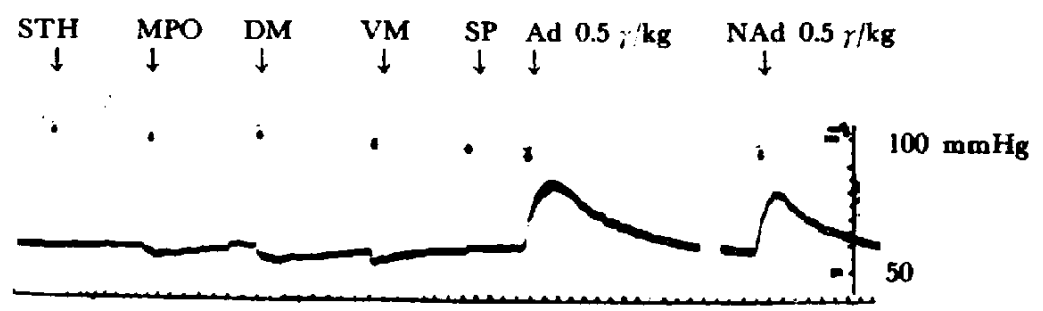

FIG. 3. The effects of the intravenous injection of $1.0 \mathrm{mg} / \mathrm{kg}$ of reserpine on the pressor responses of the urethanized rabbit to stimulation of the thalamus, hypothalamus and splanchnic nerve (10 hours after reserpine injection). Time Scale : 1 min

\section{3) Effects of amphetamine, cocaine or ephedrine on the action of reserpine}

The rise of blood pressure induced by stimulation of the hypothalamus, thalamus and splanchnic nerve was not affected or slightly potentiated by intravenous injection of 0.5 to $1.0 \mathrm{mg} / \mathrm{kg}$ of amphetamine, $2.0 \mathrm{mg} / \mathrm{kg}$ of cocaine or $0.5 \mathrm{mg} / \mathrm{kg}$ of ephedrine. Pretreatment with one of these agents did not significantly affect the initial slight action of reserpine ( $1.0 \mathrm{mg} / \mathrm{kg})$ within 2 to 3 hours after the intravenous injection (Fig. 1). However, as time lapsed, the pressor responses were gradually depressed as was in the animal with reserpine alone, and 10 to 20 hours later the responses were completely abolished or markedly depressed.

The intracarotid injection of $0.1 \mathrm{mg} / \mathrm{kg}$ of reserpine did not initially affect the pressor responses even in the animal pretreated with amphetamine, cocaine or ephedrine intracarotidally. However, 10 to 20 hours after the injection of reserpine the pressor responses 

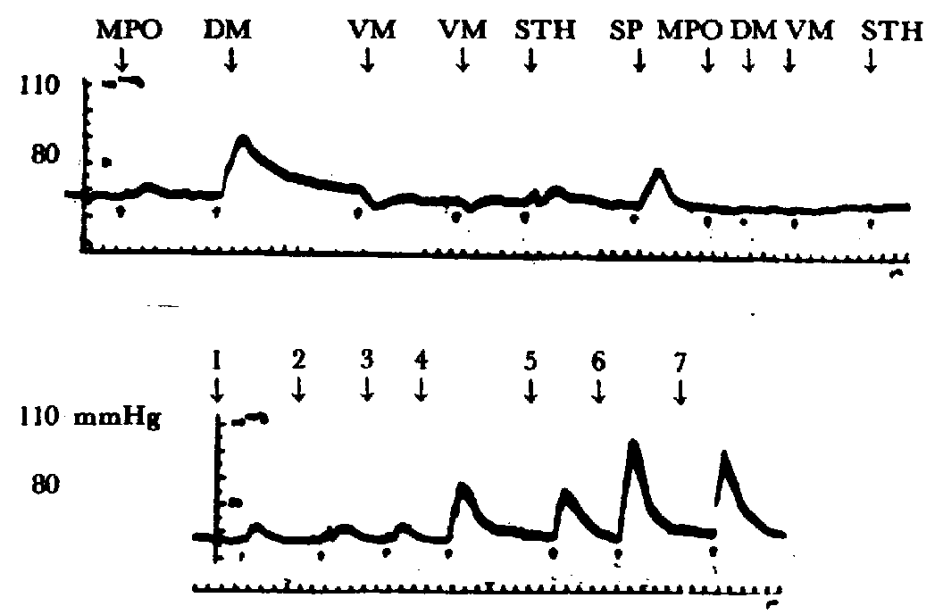

FIG. 4. The effects of the intracarotid injection of $0.1 \mathrm{mg} / \mathrm{kg}$ of reserpine on the pressor responses of the urethanized animal, treated with 0.1 $\mathrm{mg} / \mathrm{kg}$ of amphetamine intracarotidally, to stimulation of the thalamus, hypothalamus and splanchnic nerve (10 hours after reserpine injection). Time Scale : 1 min
1. NAd $0.06 \gamma / \mathbf{k g}$
3. NAd $0.06 \mathrm{r} / \mathrm{kg}$
5. NAd $0.6 \gamma / \mathrm{kg}$
7. NAd 2 r/kg
2. Ad $0.03 r / \mathrm{kg}$
4. Ad $0.3 r / \mathbf{k g}$
6. Ad $1 r / \mathrm{kg}$

to stimulation of the thalamus and hypothalamus were markedly depressed, while the response to splanchnic stimulation was not affected. Figure 4 shows the effect of the intracarotid injection of $0.1 \mathrm{mg} / \mathrm{kg}$ of reserpine on the pressor responses to thalamic, hypothalamic and splanchnic stimulation in the animal pretreated with amphetamine.

\section{Effects of Reserpine on the Pressor Responses to Adrenaline and Noradrenaline}

The pressor response to 1 to $5 \mu \mathrm{g} / \mathrm{kg}$ of adrenaline was sometimes depressed within 30 minutes after injection of reserpine, while in the case of noradrenaline it was not markedly affected. Thereafter the blood pressure rise induced by adrenaline or noradrenaline was potentiated. These potentiating effects became more and more intensive with the lapse of time. The maximal potentiation was so evident 10 to 20 hours after the injection of reserpine that even $0.05 \mu \mathrm{g} / \mathrm{kg}$ of adrenaline caused a rise of blood pressure similar to that of the normal rabbit in response to $1.0 \mu \mathrm{g} / \mathrm{kg}$ of adrenaline. The intracarotid injection of $0.1 \mathrm{mg} / \mathrm{kg}$ of reserpine also potentiated the pressor response to the intravenously administered adrenaline or noradrenaline, and this potentiating effect also became more marked with the lapse of time.

Neither intravenous nor intracarotid injection of amphetamine, cocaine or ephedrine significantly affected the pressor response to adrenaline or noradrenaline.

\section{DISCUSSION}

The intravenous injection of $1.0 \mathrm{mg} / \mathrm{kg}$ of reserpine induced a characteristic sedation with manifestation of miosis, ptosis, body temperature fall and diarrhea in rabbits. These 
symptoms developed gradually and reached their maxima 5 to 10 hours after the injection of reserpine. The sedative effect continued over 10 hours and after that returned gradually to normal within 1 to 2 days. On the other hand, the intracarotid injection of 0.1 $\mathrm{mg} / \mathrm{kg}$ of reserpine did not induce the characteristic sedation. The animal rather showed a slight excitation in motor movements. If it could be assumed that the sedative effect of reserpine is derived from its specific action on some central structures, the results would appear to show that the intracarotidally administered reserpine did not pass through the blood-brain barrier and did not reach the central region. However, it seems unlikely, because Hess and Shore (13) and Chen and Bohner (14) showed clearly that even after the intravenous injection, reserpine was distributed widely throughout brain tissues. The next point to be considered is that metabolites of reserpine would have a sedative effect but the biochemical process responsible for this metabolites might not be involved in the central nervous system. Such assumption would be also denied, because the normal metabolites of reserpine, reserpine acid and trimethoxy benzoic acid, are known to have only a minor reserpine-like effect (21).

It thus may be concluded that the sedation by reserpine cannot be ascribed only to effects on the central nervous system. Recently, Quinn et al. (22) presented a new type of tranquillizer, tetrabenazine, which releases catecholamines selectively from the central nervous system. On the other hand, Hughes Orlans $e$ al. (23) showed that a semi-synthetic analogue of reserpine, syrosingopine, a potent releaser of the heart catecholamines, had only a weak sedative effect in experimental animals. Though the introduction of these drugs of a new type may help the assumption that the reserpine sedation results from some mechanism, probably depletion of catecholamines and serotonin, in the central nervous system, reliable evidence is still lacking.

The pressor response to stimulation of the thalamic and hypothalamic nuclei was reported by Shimamoto and Oyaizu (20) as being sympathetic in origin. Impulses triggered by electrical stimulation of these areas are transmitted to the splanchnic nerve via the spinal cord. The intravenous injection of $2.0 \mathrm{mg} / \mathrm{kg}$ of reserpine markedly depressed or abolished the pressor responses to thalamic and hypothalamic stimulation. These depressant effects of reserpine coincided with a manifestation of sedation. Ten to 20 hours after the injection of reserpine all the pressor responses were completely abolished. However, from these results it can not always be concluded that the abolition of the pressor responses is ascribed only to the central action of reserpine, because the response to splanchnic stimulation was also simultaneouly blocked by reserpine. It is more conceivable that the abolition of the pressor responses to thalamic and hypothalamic stimulation occurs peripheral to the splanchnic nerve, even though an abolition in the central levels is not entirely excluded.

The evidence that reserpine releases cateholamines and serotonin from their bound forms and induces a transient increase of the circulating amines, and consequently a depletion of the amines in tissues, has been presented by many workers. Usually, the depletion of catecholamines was parallel with that of serotonin (24). Kroneberg and Schümann 
(25) concluded that the site of reserpine action was central, from the evidence that the depletion of catecholamines in the adrenal medulla induced by reserpine was reduced in grade following denervation of the splanchnic nerve in rabbits.

That the splanchnic nerve of the sedate animal shows no response to maximal stimulation seems to be as a result of depletion of catecholamines in the adrenal medulla induced by reserpine. The results that the animal injected with reserpine intracarotidally responded well to thalamic, hypothalamic and splanchnic stimulation, may admit the presumption that reserpine has no sites of action in the central nervous system. However, Halzbauer and Vogt (10) showed that reserpine depleted catecholamines and serotonin from the brain, especially from the hypothalamus. They concluded that the depletion of these amines in the brain may not be correlated with the development of sedation nor the reduced responses to thalamic and hypothalamic stimulation.

It has already been reported that such structures as the nictitating membrane of the cat, treated with reserpine and consequently followed by a marked reduction of the content of catecholamines, become hypersensitive to the transmitter substance, as seen in the denervated structure $(26,27)$. It would be easy to consider that even though the intracarotidally injected reserpine depletes catecholamines from the brain, the brain tissues might be hypersensitive to the circulating transmitter substances which are derived from unimpaired peripheral liberation. This is the explanation as to why no sedation but rather an excitatory response in behavior is seen in the case of intracarotid administration of reserpine. This assumption might lead to the conclusion that the arousal or awaked state of the brain would be maintained, or regulated, not only by the action of catecholamines of the brain but also by the circulating amines.

Brodie et al. (17) ascribed the motor excitation induced by reserpine in iproniazidtreated animals to the accumulation of released serotonin. Evidence that not only iproniazid but also amphetamine, cocaine or ephedrine reversed the sedation with reserpine to excitation was demonstrated in this experiment. The intracarotid injection of reserpine to the animal pretreated with iproniazid induced slight excitations of the motor movement and sympathetic activity. Similar procedures with amphetamine, cocaine or ephedrine also modified the response in the same way. These facts show that the accumulation of catecholamines or serotonin due to the inhibition of monoamine oxidase, or an altered responsiveness of the brain cells by these agents, may cause the transient excitation instead of the usual sedation.

All the results mentioned above indicate that sedation and excitation of the central nervous system, especially, of the thalamus and hypothalamus are correlated, in one part with the concentration of catecholamines in the brain, and in another part with the altered responsiveness of the brain cells in which concentrations of the bound amines play an important role, and further with the concentration of the circulating amines.

The mechanism of transient motor response to mechanical stimuli in the seemingly sedate animal, which was pretreated with iproniazid, amphetamine, cocaine or ephedrine and showed a usual sedation 10 to 20 hours after the injection of reserpine, was too dif- 
ficult to explain. Carlsson et al. (28) showed that treatment of the animal with a monoamine oxidase inhibitor decreased the release of catecholamines by reserpine. If this is true, the sedation in this animal should be interpreted as the result of incomplete release of catecholamines from the brain and circulating blood. The brain tissues obtaining the hypersensitivity to the transmitter substance may be able to respond to a minute concentration of free catecholamines, but this may not be enough to maintain normal movements.

The masked sedation and the abolition of the pressor responses to central stimulation which developed 10 to 20 hours after the intracarotid injection of reserpine under the pretreatment with amphetamine, cocaine or ephedrine may have resulted from the accumulation of local and circulating amines. The hypersensitized brain cells may be blocked by excessive concentrations of the transmitter substances. These discussions are open to a direct proof.

\section{CONCLUSIONS}

The effects of reserpine on the behavior of the intact rabbit and on the pressor responses of the urethanized rabbit to hypothalamic, thalamic and splanchnic stimulations were studied.

1. The intravenous injection of $1.0 \mathrm{mg} / \mathrm{kg}$ of reserpine gradually manifested a characteristic sedation and a depression or abolition of the pressor responses, and these depressive effects were most prominent 10 to 20 hours after the injection.

2. Pretreatment of the animal with iproniazid $(50$ to $100 \mathrm{mg} / \mathrm{kg}$ i.p., 24 hours previously), amphetamine ( 0.5 to $1.0 \mathrm{mg} / \mathrm{kg}$ i.v., 30 minutes to one hour previously), cocaine (2.0 $\mathrm{mg} / \mathrm{kg}$ i.v., 30 minutes previously) or ephedrine $(0.5 \mathrm{mg} / \mathrm{kg}$ i.v., 30 minutes previouly) modified the response to reserpine. The injection of reserpine caused a motor excitement with an increased sympathetic activity in the animal pretreated with one of these agents. Ten to 20 hours later, the animal was in a state of sedation, as in the non-treated animal. Even during this stage of sedation, however, the animal responded with motor movements for a while to nociceptive mechanical stimuli. The blood pressure was raised transiently in the early stage of the intravenous injection of reserpine. Ten to 20 hours later, a depression or abolition of the pressor responses was seen.

3. The intracarotid injection of $0.1 \mathrm{mg} / \mathrm{kg}$ of reserpine did not manifest sedation nor excitation even 10 to 20 hours after the injection of reserpine. The pressor responses were also not significantly modified.

4. Rabbits which were pretreated with the intracarotid injection of amphetamine ( 0.05 to $0.1 \mathrm{mg} / \mathrm{kg}, 1$ hour), cocaine $(0.2 \mathrm{mg} / \mathrm{kg}, 1$ hour $)$ or ephedrine $(0.05 \mathrm{mg} / \mathrm{kg}, 1$ hour $)$ showed a motor excitement with an increased sympathetic activity as the response to the intracarotid injection of $0.1 \mathrm{mg} / \mathrm{kg}$ of reserpine. Ten to 20 hours after the injection the animal fell into a state of sedation, during which nociceptive mechanical stimulation could awake the animal and induce motor movement for a while.

The pressor responses to thalamic and hypothalamic stimulation of the animal pre- 
treated with amphetamine, ephedrine or cocaine intracarotidally were markedly depressed, and after repetition of the stimulation the responses completely disappeared, while the response to splanchnic stimulation was not modified.

5. The hypersensitivity of the pressor response to adrenaline or noradrenaline in the animal received reserpine intravenously or intracarotidally was not significantly modified by pretreatment with iproniazid, amphetamine, cocaine or ephedrine.

\section{REFEKENCES}

1) BeIN, H.J. : Am. N.Y. Acad. Sci. 61, 4 (1955)

2) Plummer, A.J., Earl, A., Schnelder, J.H., Trapold, J. and Barkett, W. : Bid. 59,8 (1954)

3) Bein, H.J. : Pharmacol. Reo. 8, 435 (1956)

4) Bhargava, K.P. and Borison, H.L. : J. Pharmacol. 119, 395 (1957)

5) Harkison, F. and Goth, A. : Bbid. 116, 262 (1956)

6) ANAND, B.K. el al. : Brit. J. Pharmacol, 12, 8 (1957)

7) Sghneider, J.A. : Amer. J. Physiol. 181, 64 (1955)

B) Shore, P.A., Silver, S.L. And Brodie, B.B. : Science 122, 284 (1955)

9) Brodie, B.B., Olin, J.S., Kuntzman, R.G. and Shore, P.A. : Brid. 125, 1293 (1957)

10) Holzbauer, M. And VogT, M. :J. Neurochem. 1, 8 (1956)

11) Burger, M. : Helv. physid. acta 14, C13 (1956)

12) TAKETOMO, Y. A al. : J. Pharmacol. 119, 188 (1957)

13) Hess, S.M., Shore, P.A. ANd Brodie, B.B. : lbid. 118, 84 (1956)

14) Chen, G. ANd Bohner, B. : Ibid. 119, 559 (1957)

15) TORI, H. : Folia pharmacol. japon. 55, 1227 (1959)

16) TORII, H. : Bbid. 56, 1296 (1960)

17) Brodie, B.B. at al. : Ann. N.Y. Acad. Sci. 66, 631 (1957) ; J. Pharmacal. 116, 9 (1956)

18) Chessin, M., Kramer, E.R. ANd SCOTT, C.C. : lbid. 119, 453 (1957)

19) SAwyer, C.H. et al. : J. comp. Neuml. 101, 801 (1954)

20) Shimamoto, K. and Oyajzu, S. : Jap. J. Pharmacol. 8, 173 (1959)

21) Plummer, A.J., Barkett, W.E. and Rutjedge, R.A. : Fed. Proc. 13, 395 (1954)

22) QUINN, G.P. et al. : J. Pharmacol. 127, 103 (1959)

23) Hughes Orlans, F.B. at al. : Ibid. 128, 131 (1960)

24) Brodie, B.B. at al. : Psychotropic Drugs, edited by GaratTini, S. and Ghert, V. p. 423, Elsevier Publ. Co., Amsterdam (1957)

25) Kronegerg, G. and Schümann, H.J. : Arch. exp. Path. Pharmak. 231, 349 (1957)

26) Burn, J.H. AND RAND, M.J. : J. Physid. 144, 314 (1958)

27) Shimamoto, K. and Nakamura, K. : Jap. J. Pharmacol. 9, 150 (1960)

28) Carlsson, A., Rosengren, E., Bertler, A. and Nilsson, J. : Psychotropic Drugs, edited by GaratTuni, S. and Ghetri, V. p. 363, Elsevier Publ. Co., Amsterdam (1957) 